\title{
An Integrated Approach to Climate Change, Income Distribution, Employment, and Economic Growth ${ }^{*}$
}

\author{
Lance Taylor ${ }^{1}$, Duncan K. Foley ${ }^{1}$, and Armon Rezai ${ }^{2}$
}

\begin{abstract}
A demand-driven growth model involving capital accumulation and the dynamics of greenhouse gas (GHG) concentration is set up to examine macroeconomic issues raised by global warming, e.g. effects on output and employment of rising levels of GHG; offsets by mitigation; relationships among energy use and labor productivity, income distribution, and growth; the economic significance of the Jevons and other paradoxes; sustainable consumption and possible reductions in employment; and sources of instability and cyclicality implicit in the two-dimensional dynamical system. The emphasis is on the combination of biophysical limits and Post-Keynesian growth theory and the qualitative patterns of system adjustment and the dynamics that emerge.
\end{abstract}

JEL classifications: E12, E2, Q54

Keywords: Demand-driven growth, climate change, demand and distribution, energy use, energy productivity, labor productivity, employment

March 2014

\footnotetext{
${ }^{1}$ Department of Economics, New School for Social Research.

${ }^{2}$ Department of Socio-Economics, Vienna University of Economics and Business and IIASA, corresponding author: Welthandelsplatz 1, 1020 Vienna, Austria, arezai@wu.ac.at.

* This research is part of the Research Project on Sustainability, Distribution, and Stability supported by the Institute for New Economic Thinking and the Schwartz Center for Economic Policy Analysis. Rezai acknowledges financial support from the OeNB Anniversary Fund (grant no. 15330).
} 


\section{Introduction}

This paper presents a demand-driven model of interactions between greenhouse gas (GHG) accumulation, global warming, and economic growth. The goal is to avoid weaknesses of models usually deployed to address these issues.

Mainstream economists follow the neoclassical tradition and analyze the impacts of global warming on macroeconomic growth from a supply-side perspective. All resources, especially labor, are supposed to be fully employed, so that total spending on investment and climate mitigation is determined by available saving. Following Keynes (1936) this set of assumptions is often called "Say's Law." The most widely discussed climate change models such as Nordhaus (2010) further assume that decisions about investment and mitigation are taken by a "representative agent" which maximizes discounted utility from consumption over a time horizon spanning centuries. The Nordhaus model has severe technical drawbacks (Rezai, Foley, and Taylor, 2012) but more fundamentally its key assumptions are not convincing. Will labor be fully employed if global warming significantly reduces the level of output? Does the optimizing agent make any institutional sense? There is good reason to think that the answer to both questions is No, especially in a world of countries with conflicting interests.

Economists following the tradition of Ecological Economics, such as Victor (2008) and Jackson (2009), view global warming from another angle. They advocate "sustainable consumption." Sustainability in this sense implies that the growth rate of consumption per capita should be low or negative (to be complemented by restructuring the consumption basket in favor of less energy-intensive goods). But then will spending on investment or mitigation rise to absorb an increase in the saving share of income? This response occurs automatically in neoclassical growth models which rule out Keynes's "Paradox of Thrift" whereby a higher saving rate leads to a lower level of output.

There are also problems with a high saving rate in the "long run." A widely accepted convention in economic growth theory is that a model should be set up to force the variables in a macro system toward a stable attractor or "steady state" in which they all increase (or decrease) at the same exponential rate (perhaps zero or negative). Ratios of variables such as output/capital or employment/population become constant. In model simulations the trajectories that variables 
follow toward the same growth rate are strongly influenced by the nature of the steady state (the stable attractor) itself.

At a steady state, the presence of global warming implies that to avoid an ever-increasing concentration of GHG there should be zero or negative population growth and a stable level of per capita consumption. ${ }^{1}$ The implication is that eventually a low saving rate will be required. Saving would only be needed to pay for mitigation to offset emissions from ongoing production and to maintain a constant level of the capital stock per capita by financing investment to make good the loss of productive capacity due to depreciation.

Finally, Schor (2010) and others suggest that the adverse effects in the labor market due to lower consumption could be supported by a reduction in employed labor time (through either open unemployment or fewer working hours per year). This idea raises complications involving output determination, shifts in productivity, and patterns of energy use which are discussed below. The difficulties are related to a Keynesian "lump-of-labor" paradox (usually called a "fallacy" by mainstream economists) whereby total employment is a direct function of output as determined by aggregate demand. This paradox means that labor cannot be "applied" directly to mitigate climate change, a common neoclassical prescription. The application can occur only if demand for labor is increased by, for example, higher spending on GHG mitigation.

Our main aim is to present a model that combines biophysical limits in the form of atmospheric greenhouse gas concentration and Post-Keynesian growth theory. The model is set up in terms of two "state" or "slow" variables that evolve over time - the capital/population ratio and the level of GHG concentration. Following another convention in growth theory, in the model's "short run" of about a decade both are treated as constant. They determine rapidly adjusting or "fast" variables such as the profit rate, output, the level of labor productivity, etc. ${ }^{2}$

Under "appropriate" assumptions the two slow variables may converge over time to a quasi-steady state in which the ratio of capital to population is constant, and GHG concentration is stable or falling. In contrast to most growth models there is no particular reason for such convergence to be monotonic; there are several ways in which oscillations around a unique

\footnotetext{
${ }^{1}$ Strictly speaking, if there were positive population growth at constant per capita income, then GHG emission could be held stable by devoting an ever-increasing share of output to mitigation, but with increasing costs of mitigation (as assumed below) that strategy would ultimately fail.

${ }^{2}$ The model's short period of ten years is long enough to allow macroeconomic business cycle fluctuations, which (along with mainstream climate change models) we simply ignore.
} 
steady state could arise. Moreover, destabilizing positive feedbacks in the system may simply make it diverge. Climate policy has the potential to lower the carbon intensity of output but also to increase energy efficiency. Both policy instruments have stabilizing effects. Our analysis extends the verbal analysis of Rezai, Taylor, and Mechler (2013) and presents a consistent modeling framework for the questions outlined above. Section 2 introduces the essential elements of a demand-driven growth model which incorporates energy use and greenhouse gas emission. Section 3 discusses the short run determination of output. Section 4 introduces income distribution to the model. Sections 5 and 6 turn to the growth of labor productivity and the dynamics of output and capital stock. Section 7 brings in energy use and the dynamics of greenhouse gas accumulation. Section 8 presents the analysis of the interaction of greenhouse gas accumulation and economic growth and section 9 concludes.

\section{Demand-Driven Growth}

Any theory of economic growth must incorporate a narrative about how the economy evolves in what Joan Robinson (1974) called a model's "logical" (certainly not observable chronological) time. It makes sense to sketch out the model verbally before jumping into the mathematics.

Over the past 25 years a lot of effort has been devoted to working out demand-driven growth models that incorporate shifts in the income distribution. Taylor (2010) presents a moderately accessible, non-technical survey. In the present model's short run, saving and investment respond positively to a rise in the profit rate. Effects on output and capital accumulation can depend on several factors.

First, if the increase in investment is strong enough it can overcome the paradox of thrift so that output, employment, and the growth rate of the capital stock go up. Such a "profit-led" adjustment to a shift in the income distribution may be characteristic of (at least) high income economies.

Second, higher atmospheric GHG concentration can reduce profitability and investment demand. On the other hand an increase in expenditure on mitigation will boost output and thereby GHG emission, in a macroeconomic version of the "Jevons paradox" or "rebound effect" 
recently emphasized by ecological economists. Whether the induced increase in emission will overwhelm the reduction due to greater mitigation is ultimately an empirical question in simulation of equation (11) below.

Third, in the same time frame there is a thought dating back to Marx that a tighter labor market (as signaled by an increase in the employment/population ratio) will tend to reduce the profit share. This negative feedback means that any initial profit surge and increased economic activity will be at least partly offset by an induced "profit squeeze."”

Finally, the level of labor productivity may change in the short run in response to several factors. It may rise with a higher level of investment, an increase in "energy intensity" or the energy/labor ratio, and lower employment. On the other hand, higher GHG concentration can reduce productivity.

Investigating how all these short-run interactions play out is our initial task. Over time, moreover, investment will lead to capital stock accumulation as the size of the economy expands. An immediate question is whether the capital/population ratio will eventually stabilize in a steady state. In the one-dimensional model sketched so far, convergence to a steady state is likely, accompanied by a fairly tight labor market and a low rate of profit. A key to deriving this result is an accounting identity linking the ratios capital/population and output/employment (that is, labor productivity) to the ratios output/capital and employment/population. Possible productivity changes as just discussed also have to enter into the analysis.

Global warming is brought in through two additional identities. One says that energy intensity is equal to labor productivity divided by the output/energy ratio (or energy productivity). Second, in a variation on the well-known "Kaya identity" from climate science (Waggoner and Ausubel, 2002) one can set up a differential equation for the growth rate of GHG, and for ease of analysis extend it to an equation for the growth of the GHG/capital ratio. Together with the growth equation for capital/population this relationship enters into a twodimensional dynamical system which can generate diverging, cyclical, or stably converging trajectories for the two variables which are illustrated diagrammatically.

\footnotetext{
${ }^{3}$ There is an alternative to this "profit-led/profit squeeze" model. Demand may be "wage-led" (rising when the profit share falls) and there may be a "wage squeeze" when output rises. It would be natural to assume in this formulation that higher GHG concentration cuts into the wage (instead of the profit) share. Such a specification is beyond the scope of this paper.
} 
A full analysis, which would require numerical calibration and simulation, is not attempted here. Rather we focus on setting up accounting and behavioral assumptions and the study of the dynamic behavior of the resulting system which could be elaborated in simulation. Using linear approximations, dynamics around steady states are explored. The text concentrates on a single economy, with extensions toward the multi-economy case briefly sketched in Appendix I. Appendix II briefly sketches how supply-driven climate change models are set up.

\section{Output and Investment}

We begin our analysis with determination of the level of economic activity in a shortterm growth and distribution model. Let $X$ be real output, $C$ consumption, $I$ investment (including inventory accumulation and gross fixed capital formation), and $M$ expenditure on GHG mitigation. All these variables should be interpreted as "flows" (trillions of dollars) per unit of time.

Suppose that $C=[1-s(\pi)] X$ in which $s(\pi)$ is the saving rate treated as an increasing function of the share $\pi$ of profits in total income (in turn equal to output). With $s_{\pi}$ and $s_{w}$ as shares of profit and wage income that are saved, a convenient expression for the overall saving rate is $s=s_{w}+\left(s_{\pi}-s_{w}\right) \pi$. If saving rates for profit income are higher than those for wage income which is consistently observed for all developed economies, redistribution toward profits leads to a higher aggregate saving rate (i.e., $d s / d \pi>0$ for $s_{\pi}>s_{w}$ ).

The macro balance equation is

$$
X=C+I+M=[1-s(\pi)] X+I+M .
$$

Along lines proposed by Kalecki (1971) assume that gross fixed capital formation is driven by the profit rate $r=\pi u$ with $u=X / K$ ( $u$ stands for "utilization")

$$
I=\left(g_{0}+\alpha \pi u\right) K
$$

It is convenient to scale spending on mitigation to output, $M=m X$, and investment to the capital stock, $I=g K$. Macro balance becomes

$$
X=[1-s(\pi)] X+\left(g_{0}+\alpha \pi u\right) K+m X
$$

or 


$$
s(\pi) u=g+m u=\left(g_{0}+\alpha \pi u\right)+m u
$$

so that saving finances investment and mitigation. In these equations $X$ is proportional to $K$, i.e. utilization $u$ does not depend directly on the level of $K$. Utilization is, however, a function of $\pi$ (which as we will see does depend on $K$ ), determined from an effective demand relationship

$$
u(\pi)=\frac{g_{0}}{s(\pi)-m-\alpha \pi}
$$

with $g_{0}$ and $m$ as parameters (perhaps influenced by policy). If demand is profit-led the $u(\pi)$ schedule will slope upward in Figure 1. ${ }^{4}$

\section{Figure 1}

The gross investment schedule (written two ways) is

$$
g(\pi)=[s(\pi)-m] u=\frac{[s(\pi)-m] g_{0}}{s(\pi)-m-\alpha \pi},
$$

again depending on $K$ only through changes in $\pi$.

\section{Distribution}

Supply-driven climate models typically incorporate a "damage function" which indicates the degree to which full employment output is directly reduced by an increase in GHG concentration $G$, currently on the order of $395 \mathrm{ppmv}$ (parts per million by volume). Because output is determined by demand, the present model cannot admit such a simple relationship. To find the level of capacity utilization, one has to bring in responses of the profit share $\pi$ to changes in $G$, the capital/population ratio $\kappa$, and labor productivity $\xi=X / L$ with $L$ as employment.

Through changes in effective demand, $u$ and $g$ will respond to these variables. Besides a direct negative impact of $G$ on $\pi$, higher GHG concentration could reduce productivity as

\footnotetext{
${ }^{4}$ Equation (2) differs from the standard multiplier expression $u=g_{0} / s$ because of the $-m$ and $-\alpha \pi$ terms in the denominator. The former captures the positive Jevons effect of higher mitigation spending on output and the latter reflects the feedback of higher economic activity into investment demand. Because it enhances the effect on output of the demand injection $g_{0}$ a formula like (2) is sometimes said to incorporate a "super-multiplier."
} 
discussed below. GHG accumulation could also destroy capital, either directly (say a Category V hurricane hits the Houston ship channel and wipes out $10 \%$ of US refining capacity) or via more rapid depreciation.

To trace through these possibilities we have to set up a profit share schedule $\pi(u)$ to use together with the $u(\pi)$ curve in Figure 1. Ignoring complications arising from shifts in labor force participation rates, let $N$ be the total population. Then the employment rate is $\lambda=L / N$. Finally $\kappa=K / N$ is the capital stock per capita.

The identity that was mentioned above links these variables with economic activity,

$$
\lambda=\kappa u / \xi
$$

At any point in time, $\kappa$ will be determined by the history of capital accumulation and population growth. Productivity $\xi$ can be assumed either to be exogenous (possibly with a shifting trend), or else determined by a "technical progress function" as discussed below. Either way, (4) says that $\lambda$ is proportional to $u$.

In several passages in Capital, Marx sketched a theory of business cycles (later formalized by Goodwin, 1967) pivoting on shifts in the income distribution. At the bottom of a cycle, the real wage is held down by a large reserve army of un- or under-employed workers, and capitalists can accumulate freely. However, as output expands the reserve army is depleted and $\lambda$ goes up. The real wage rises in response to a tighter labor market, forcing a profit squeeze. Capitalists search for new labor-saving technologies and also invest to build up the stock of capital and reduce employment via input substitution. Excessive funds tied up in machinery, sectoral imbalances, and lack of purchasing power on the part of capitalists to sustain investment (or on the part of workers to absorb the output that new investment produces) can all underlie a cyclical collapse. The model of this paper extends this cyclical dynamics toward the long run. A simple formulation is that a higher level of $\lambda$ reduces $\pi$ in an equation such as

$$
\pi=\phi(\lambda, G)=\phi(\kappa u / \xi, G) .
$$


As observed above, higher GHG concentration may cut into profitability so that in (5) $\partial \phi / \partial \lambda$ and $\partial \phi / \partial G$ are both negative (signs of the $2^{\text {nd }}$ partial derivatives could be important in practice). First order relationships are illustrated as the $\pi(u)$ schedule in Figure 1. ${ }^{5}$

Now consider the effects of possible changes. For a given $u$, lower labor productivity $\xi$ (treated for the moment as exogenous) will increase $\lambda$ and make the profit share fall. After the $\pi(u)$ curve shifts downward, both $\pi$ and $u$ would decline. A similar outcome occurs via the direct negative effect of higher $G$ on $\pi$ in (5) - the demand-driven analog of the GHG damage function in mainstream models.

On the other hand a lower level of $\kappa$ (capital destruction) will increase both variables, as the $\pi(u)$ schedule shifts up. The implication of the rise in $u$ is that output and employment decrease less than in proportion to the capital stock. Even though $\pi$ goes up there is an adverse effect of less capital on economic activity. ${ }^{6}$

If shifting toward sustainable consumption means that the overall saving rate rises, then because of the paradox of thrift the $u(\pi)$ schedule would move to the left (or "down") leading to lower $u$ and higher $\pi$. More spending on mitigation would shift the schedule back toward the right, driving economic activity (and GHG emission) back up.

\section{The Role of Productivity}

Mainstream growth models of climate change usually assume that labor productivity $\xi$ is exogenous. But in the Keynesian tradition productivity has long been treated as endogenous in the macro system. Given the decadal duration of the present model's short run, it makes sense to treat $\xi$ as a "fast" variable.

Kaldor $(1957,1978)$ worked with a "technical progress function." The basic idea is that faster output growth and/or higher investment will permit production to take place with

\footnotetext{
${ }^{5}$ In standard national accounting, output $X$ would be measured as real value-added. Hence a lower $\pi$ would have to be met by higher labor share $\psi=1-\pi=\omega / \xi$ with $\omega$ as the real wage. It is assumed below that energy use $E$ is proportional to output, $\varepsilon=X / E$, with $\varepsilon$ as energy productivity. The quantity $Z=\left(1+\varepsilon^{-1}\right) X$ would be a natural definition of "gross" real output, and a change in $\pi$ would normally be reflected into changes in the shares of labor and the total cost of energy $P_{e} E$ with $P_{e}$ as the price of energy in a larger value aggregate corresponding to $Z$. For simplicity this accounting detail is omitted here.

${ }^{6}$ In terms of the Houston ship channel example mentioned above, $\pi$ would presumably rise due to higher gasoline prices, stimulating investment demand to help offset the destruction of capital.
} 
decreasing costs and also allow more advanced technologies to be brought into play. For present purposes, $\xi$ can be treated as an increasing function of the investment/capital ratio $g$.

Another line of thought suggests that output may not be strongly curtailed by a reduction in employment, basically because productivity goes up. In the US in 1930, this idea justified an apparently successful cut in the length of the working day by the Cornflakes tycoon W. K. Kellogg. Advanced by Sen (1966), it showed up in debates during the 1960s about surplus labor in developing economies - withdrawing labor from a "subsistence" sector was supposed to reduce the level of production by very little. The implication is that $\xi$ may be a decreasing function of $\lambda$. Because $\lambda=\kappa u / \xi$ from (4), this linkage induces a positive feedback from $\xi$ into its own level.

Energy can also play a role in the determination of labor productivity. Let $\varepsilon=X / E$ stand for energy productivity. If $e=E / L$ is "energy intensity" then a useful identity follows immediately,

$$
e=\xi / \varepsilon
$$

Available data can be used to illustrate this accounting. There appears to be a robust relationship between increasing energy use per worker and labor productivity (Taylor, 2009), with an elasticity possibly exceeding one (meaning that there is a positive relationship between energy intensity and energy productivity). These observations are consistent with the view expressed by Smil (2005) and many others that much productivity-increasing technical change relies on higher energy use per unit employment.

Finally, higher GHG concentration can cut directly into productivity. The upshot is a relationship of the form

$$
\xi=\theta(g, \lambda, e, G ; t) .
$$

The Kaldor effect shows up via $g$, with $\partial \theta / \partial g>0$. The Kellogg-Sen productivity link means that $\partial \theta / \partial \lambda<0$. The energy linkage is $\partial \theta / \partial e>0$, with energy productivity $\varepsilon$ following from (6). The GHG impact means that $\partial \theta / \partial G<0$. Finally, productivity may shift over time $t$ with a partial derivative that eventually goes to zero.

From equations (3) and (4) above, $g$ and $\lambda$ respectively will be related positively to $u$ so that the sign of the (indirect) partial derivative $\partial \xi / \partial u$ is ambiguous. From (4) there will be a 
negative impact of $\kappa$ on $\xi$, and the positive feedback effect of $\xi$ on its own level has already been noted. $^{7}$

Figure 2 illustrates the implications of bringing productivity into the picture, with $u$ and $\xi$ as the relevant variables. The $\xi(u)$ schedule will have a positive slope when there is a dominant Kaldor effect of utilization $u$ (via $g$ ) on productivity. The slope of the line through the origin in the diagram running through an initial equilibrium point $\mathrm{A}$ is $\xi / u=K / L$ so that points to its left (right) have lower (higher) employment than the level at A. With its relatively weak positive effects of each variable on the other, the diagram represents a stable short-term equilibrium.

\section{Figure 2}

The figure illustrates a situation in which higher GHG concentration reduces both variables but with a sharper reduction in labor productivity than in utilization. As a consequence, employment increases. Via (2) the profit share would fall. If one ignores the Kellogg-Sen effect in (7), then as discussed above destruction of capital could stimulate higher investment and productivity, thereby harming employment.

Figure 3 shows a dominant negative effect of $u($ via $\lambda)$ on productivity. Both utilization and productivity decline with increased GHG, with a relatively strong shift of the former causing employment to fall. Lower mitigation expenditure or higher saving would shift the $u(\xi)$ schedule to the left, reducing utilization but with ambiguous effects on productivity and the profit share.

Figure 3

\footnotetext{
${ }^{7}$ If $A=-(\partial \theta / \partial \lambda)\left(\kappa u / \xi^{2}\right)<1$ the feedback implies that the effects of other variables on $\xi$ will all be increased by a multiplier $(1-A)^{-1}$. If $A>1$, the short run equilibrium will be unstable.
} 


\section{Capital Stock Growth}

All these responses will influence the details of convergence toward (or divergence from) a steady state. To bring in growth dynamics explicitly, let $\dot{\kappa}=d \kappa / d t$ so that $\hat{\kappa}=\dot{\kappa} / \kappa$ is the growth rate of the capital/population ratio. If $\delta$ is the depreciation rate of capital and $n$ is the rate of population growth $(\widehat{N}=n)$ then the increase in $\kappa$ over time is

$$
\dot{\kappa}=\kappa(g-\delta-n) .
$$

This differential equation has a steady state solution with $\dot{\kappa}=0$. It is

$$
g=\delta+n
$$

or from (1),

$$
s u=\delta+n+m u \text {. }
$$

In terms of annual rates, the depreciation coefficient $\delta$ might be around 0.05 . If the population growth rate were zero, from (9) that would also be the value of $g$ per year. Mitigation spending as a share of output might be 0.01. A plausible value for the GDP/capital ratio might be 0.3 (say from current world GDP of about $\$ 60$ trillion and capital stock of $\$ 200$ trillion). The implication from $(10)$ is that $(s-0.01)(0.3)=0.05$ or $s=0.177$ in steady state.

To check stability of this one-dimensional dynamical system we have to evaluate the sign of the derivative $\partial \dot{\kappa} / \partial \kappa$ from (8) as constrained by (4) and (5) when condition (9) applies. Going through the exercise shows that $\partial \dot{\kappa} / \partial \kappa<0$ because $\partial g / \partial \kappa<0$, i.e. the solution of (8) tends toward a steady state. Figure 4 depicts the linearized system, with $\kappa^{*}$ as the steady state value of $\kappa$. As illustrated by the small arrows, $\kappa$ will increase when $\kappa<\kappa^{*}$ and decrease otherwise.

\section{Figure 4}

A higher level of greenhouse gas would reduce investment demand, shifting the $g(\kappa)$ schedule downward and reducing $\kappa^{*}$. The level of the steady state employment ratio $\lambda$ would depend on productivity. By causing $\lambda$ to fall and increasing the profit share, higher labor

productivity would increase $\kappa^{*}$ (or lower productivity caused by global warming would reduce 
$\left.\kappa^{*}\right)$. Consistent with the paradoxes of thrift and Jevons, a lower saving rate or higher expenditure on mitigation would raise the steady state level of $\kappa$. In a standard result from model accounting slower population growth $n$ would have the same effect.

To illustrate the implications of convergence, consider the following back of the envelope calculation. With current world employment of about 3 billion and output of $\$ 60$ trillion, $\xi=20$. The employment/population ratio is $\lambda=3 / 7=0.43$ and capital/population is $\kappa=200 / 7=$ 28.6. Suppose that at an eventual steady state productivity has doubled, $\xi=40$. If population stabilizes as currently projected at 10 billion and $\lambda$ rises to 0.5 , then steady state $X=200$. Maintaining the current value of $u=0.3$ would make $K=667$ and $\kappa=66.7$. Capital stock growth of around one percent per year for 100 years would produce this level of $K$. To double labor productivity over a century require a growth rate of $0.7 \%$, less than the historical average for rich countries of around $2 \%$.

\section{Energy Use and GHG Accumulation}

The final step is to set up accounting describing how GHG accumulation and global warming are driven by the use of energy in production, giving rise to a two-dimensional dynamical system in $\kappa=K / N$ and $G$. With both variables at a steady state, $K$ would be growing at the population growth rate $n$. Final stabilization or reduction of GHG concentration would require $n \leq 0$.

To bring GHG into the dynamics, it is convenient to work with the ratio $\Gamma=X / G$ as a measure of output per unit of atmospheric carbon. The flow increase of $G$ is described by an expression similar to the Kaya identity,

$$
\dot{G}=\chi E-\psi(m) m X-\omega G=[(\chi / \varepsilon)-\psi(m) m] X-\omega G=v X-\omega G .
$$

in which carbon emission goes up with energy use according to the coefficient $\chi=\dot{G} / E$. The function $\psi(m)$ gauges the effectiveness of mitigation in reducing emission. Presumably it is concave and decreasing so that effectiveness of mitigation decreases at an increasing rate. The overall coefficient $v=(\chi / \varepsilon)-\psi(m) m$ gives net emissions generated per unit of output, and can take either sign -- it would be negative if mitigation more than offset total emissions. Very slow natural dissipation of atmospheric $\mathrm{CO}_{2}$ is captured by the term $-\omega G$. 
Dividing both sides of (11) by $G$ gives

$$
\widehat{G}=[(\chi / \varepsilon)-\psi(m) m / u] \Gamma-\omega=v \Gamma-\omega
$$

To begin to put (very) rough numerical flesh on this equation, with GDP of $\$ 60$ trillion $\Gamma=X / G=60 / 395=0.1519$. It is simplest to think of energy use in terms of terawatts of power (as opposed to exajoules of energy per year). The current level is about 15 terawatts, of which 12 terawatts are provided by fossil fuels. Fossil fuel energy productivity becomes $\varepsilon=60 / 12=5$. This energy use generates about 7 gigatons of carbon per year, corresponding to an increase in $G$ of $3.37 \mathrm{ppmv}$. The observed increase is 2 ppmv, so that $\widehat{G}=2 / 395=0.0051$ with atmospheric dissipation of 1.37 ppmv. The dissipation coefficient in this highly stylized carbon cycle model becomes $\omega=1.37 / 395=0.0035$. Assume for simplicity that there is now no effective mitigation $(m=0)$ so that $(12)$ becomes

$$
\widehat{G}=(\chi / \varepsilon) \Gamma-\omega
$$

With carbon emissions of 3.37 and fossil fuel energy use of 12 , the ratio $\chi=3.37 / 12=0.2808$ and $v=\chi / \varepsilon=0.0562$. The balance equation for $\widehat{G}$ works out to be $0.0051 \approx(0.0562)(0.1519)-0.0035=0.0085-0.0035$. To drive the growth rate $\hat{G}$ toward zero is not an insurmountable task. If it costs about $\$ 160$ to remove one ton of atmospheric carbon (carbon markets suggest a cost level between $\$ 75$ and $\$ 125$ ), then to reduce concentration by 1.0 ppmv by removing 2.07 gigatons of carbon from emissions would cost $(2.07)(\$ 0.16$ trillion $)=\$ 0.331$ trillion. With the current level of output at $\$ 60$ trillion, setting $m=0.01$ would generate mitigation expenditure of $\$ 0.6$ trillion, enough to abate emissions by $1.812 \mathrm{ppmv}$.

From (10) and (11) the condition for a steady state with $\dot{G}=0$ is

$$
\Gamma=X / G=v / \omega
$$

again with $v=(\chi / \varepsilon)-\psi(m) m$. An "ambitious" ultimate target for $G$ might be 350 ppmv. From (13) with $\omega=0.0035$ the required level of net emissions per unit of output would be $v=0.0015$, substantially below the current value of 0.0562 . Given the way the model is parameterized, this reduction could be accomplished in several ways. One is reduction of $\chi$, or GHG emission per unit of fossil fuel use. There is room for improvement here, but perhaps not a great deal. Second, energy productivity $\varepsilon$ could be increased. From (6), $\varepsilon=\xi / e$ and it was 
assumed above that labor productivity $\xi$ will double en route to a steady state. Historically, however, $\xi$ and energy intensity $e=E / L$ have been positively correlated. Whether this linkage can be broken so that $\varepsilon$ rises more or less in proportion to $\xi$ (with a small increase in $e$ ) is very much an open question. Finally, the considerations above suggest that, subject to decreasing returns, mitigation expenditure on the order of one percent of GDP could come close to achieving a goal of 350 ppmv subject to (13).

\section{Dynamics of the Capital/Population Ratio and the GHG/Capital Ratio}

Equations (1)-(13) form our macroeconomic model of GHG accumulation and economic growth. It allows us to analyze the fundamental dynamics of the capital/population ratio and the GHG/capital ratio in a two-dimensional system. From (11) $\dot{G}$ depends on $X$. If output goes up there is faster GHG accumulation, which in turn can reduce $X$ over time. As discussed above, output ultimately is scaled by the "size" of the economy as measured by $K$. To take this feedback loop into account, it becomes useful to set up the system in terms of the GHG/capital ratio, $\gamma=G / K$. Obviously, given values of $\gamma$ and $K$ at any time, one can find $G$ for use in (5) and (7).

With $\widehat{K}=g-\delta$, dynamics of $\gamma$ around its steady state are described by

$$
\hat{\gamma}=\widehat{G}-\widehat{K}=v \Gamma-(\omega+g-\delta) .
$$

Because $\Gamma \gamma=(X / G)(G / K)=X / K=u$ this expression for the growth rate of $\mathrm{CO}_{2}$ concentration per unit of capital can be restated as

$$
\dot{\gamma}=v u-(\omega+g-\delta) \gamma
$$

With $\dot{\gamma}=0$ it will be true that

$$
\gamma=v u /(\omega+g-\delta)
$$

a rearranged version of (13).

The local stability condition for (14) is $\partial \dot{\gamma} / \partial \gamma<0$ with the derivative evaluated at the steady state described by (15). Even if $\omega+g-\delta>0$, because $\omega$ is very small this condition could be violated, leading to run-away climate change. From the discussion of Figure 1, higher levels of atmospheric carbon reduce both output and capital growth (i.e. $\partial u / \partial \gamma$ and $\partial g / \partial \gamma$ are negative). A negative value of the net emissions coefficient $v$ could therefore make $\partial \dot{\gamma} / \partial \gamma$ 
positive, with a lower value of $u$ cutting back on effective mitigation. A strongly negative value of $\partial g / \partial \gamma$ could also be destabilizing. Basically, an increase in $G$ would reduce the investment/capital ratio $g$ and the growth of $K$. A lower denominator would raise $\gamma$ further and so on.

We can examine joint dynamics $\kappa$ and $\gamma$ by using equations (8) and (14). The standard thought experiment for this sort of model starts with the assumption that the two-dimensional system is at a steady state. The differential equations are then "shocked" or "perturbed" by a change in a parameter or exogenous variable. In a "phase diagram" such as Figure 5 below for the $(\kappa, \gamma)$ plane, the position of the steady state will shift and the variables may or may not converge toward it. Their trajectories around the new steady state provide qualitative insight into the behavior of the system. The Jacobian matrix of the partial derivatives of $\dot{\kappa}$ and $\dot{\gamma}$ with respect to $\kappa$ and $\gamma$, evaluated at the new steady state, is the standard tool for this exercise. Now we dive into the details. ${ }^{8}$

In (8) we have $\partial \dot{\kappa} / \partial \kappa<0$ and $\partial \dot{\kappa} / \partial \gamma<0$. For the sake of discussion assume that (14) is well- behaved, i.e. $\partial \dot{\gamma} / \partial \gamma<0$ and $v>0$. The sign of $\partial \dot{\gamma} / \partial \kappa$ is ambiguous because both $\partial u / \partial \kappa$ and $\partial g / \partial \kappa$ are negative. For small $\nu$ and a large absolute value of $\partial g / \partial \kappa$ we would have $\partial \dot{\gamma} / \partial \kappa>0$. Basically, a higher value of $\kappa$ cuts into profits and reduces $g$ in (14). As illustrated in Figure 5, cyclicality could emerge because $\kappa$ increases $\dot{\gamma}$ while $\gamma$ reduces $\dot{\kappa}$. In the feedback loop discussed in connection with (11) more capital and higher economic activity raise GHG emission while a higher concentration of GHG reduces the level of output.

In more detail, with $\partial \dot{\gamma} / \partial \kappa>0$ the sign pattern of the Jacobian takes the form

$\begin{array}{llll} & \kappa & \gamma & \\ & & & \\ \dot{\kappa} & - & - & \\ \dot{\gamma} & + & - & \end{array}$

Two conditions govern whether or not steady state solutions to (8) and (14) are locally stable. For stability, the trace of the Jacobian must be negative and the determinant positive. Both conditions are satisfied in the matrix at hand. In practice, the determinant condition puts restrictions on the slopes of the "nullclines" along which $\dot{\kappa}=0$ and $\dot{\gamma}=0$. A steady state

\footnotetext{
${ }^{8}$ For people at ease with calculus, Hirsch, Smale, and Devaney (2012) is an excellent text on these matters.
} 
solution for both variables occurs at a point where the nullclines intersect. In (14) $\dot{\gamma}$ responds negatively to $\gamma$ and positively to $\kappa$. If $\kappa$ increases, then to hold $\dot{\gamma}=0 \gamma$ would have to increase as well - the nullcline has a positive slope. To hold $\dot{\kappa}=0$ in (8), on the other hand, a higher value of $\kappa$ would have to be offset by a lower $\gamma$ - the nullcline slopes downward. When the "off diagonal" entries in the Jacobian have opposite signs, cyclical behavior can easily occur. A common interpretation is that $\gamma$ (greenhouse gas) is a "predator" variable and $\kappa$ (productive capacity) is "prey." Figure 5 shows typical dynamic trajectories in such a system.

\section{Figure 5}

Suppose that there is an initial steady state at point A. If $v$ goes down because energy intensity $e$ is cut back (raising energy productivity $\varepsilon$ for a constant level of $\xi$ ) or the mitigation effort $m$ increases then the $\dot{\gamma}=0$ nullcline would shift downward. From the Jevons effect the nullcline for $\dot{\kappa}=0$ would rise (or shift to the right). At the new steady state B there would be a higher level of $\kappa$ which in turn would generate an increased level of per capita income $X / N$. The shift in $\gamma$ is ambiguous. As the diagram is drawn it would go down. There would be cycles in the variables as they move from A toward B. Cyclical behavior does not necessarily have to occur. Because $\partial u / \partial \kappa<0$, it could also be true that $\partial \dot{\gamma} / \partial \kappa<0$ in (14) if $v$ is relatively large (emissions per unit output are high and/or mitigation is weak). Now a higher value of $\kappa$ makes $\dot{\gamma}$ decrease from (14) and vice-versa from (8). With negative feedback of each state variable into the other the sign pattern of the two-dimensional Jacobian becomes

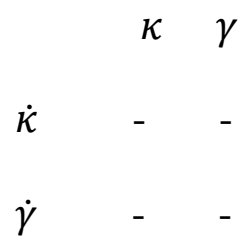

Because $\partial \dot{\gamma} / \partial \kappa$ is negative instead of positive, the $\dot{\gamma}=0$ nullcline switches to a negative slope.

If $\gamma$ strongly reduces $\dot{\kappa}$ and $\kappa$ does the same for $\dot{\gamma}$ the determinant could be negative, signaling a saddlepoint instability. The dynamics are illustrated in Figure 6. Away from the "saddlepath" SS, all trajectories diverge, with the ultimate outcome depending on initial 
conditions. For example, from an initially high level of $\gamma$ and a low $\kappa$ as at point A, both variables would increase but eventually GHG accumulation would cut into investment demand sufficiently to make $\dot{\kappa}<0$. GHG concentration would rise indefinitely, driving the economy toward collapse. This scenario resembles a solvency crisis in a debtor economy with everincreasing payments obligations which wipe out growth. If the system were to start at point B with a low $\gamma$ and high $\kappa$ the GHG/capital ratio would ultimately be driven toward zero (though GHG accumulation could still be positive!).

\section{Figure 6}

If, on the other hand, the determinant is positive and the system is stable, Figure 7 depicts the dynamics. If $v$ goes down from an initial steady state at $\mathrm{A}$ the $\dot{\gamma}=0$ nullcline again moves down and the $\dot{\kappa}=0$ schedule shifts to the right. At point B there is unambiguously a lower steady state level of $\gamma$ and a higher $\kappa$ along with increased per capita income and employment. Cycles disappear and the variables would move more or less directly from the A toward B.

\section{Figure 7}

At least three more issues arise, which can be briefly considered. One is that a steady state with zero or negative net emissions would differ markedly from current economic organization under capitalism. It is worth recalling that in historical perspective industrial capitalism wrenched workers out of much more "sustainable" (if very low standard-of-living) systems into what now appears to be unsustainable production of "output". Whether the social relations of production will remain capitalist is one question; but if we posit "sustainability", the organization of production will have to undergo fundamental changes. Some of the complications can be faintly reflected into the parameterization of the model, which will have to be consistent with steady state conditions as defined by (9), (10), (13), and (15). ${ }^{9}$ It is natural to

\footnotetext{
${ }^{9}$ I.e. the conditions: $g=\delta+n, s u=\delta+n+m u, \Gamma=v / \omega$, and $\gamma=v u /(\omega+g-\delta)$.
} 
require $n \leq 0$ in the "long run," which would imply that $g \leq \delta$ with associated levels of the socially significant variables $\pi$ and $\lambda$ and (possibly) a negative value of the net emission parameter $v$ from (12) or (14). Specifying parameters to be able to satisfy these and related restrictions is a non-trivial task.

Second, sustainable consumption would presumably involve shifts in spending patterns toward less energy-intensive sectors. It is straightforward to run a multi-sectoral demand-driven model. Again, however, setting it up in terms of parameters could be difficult.

Finally, a properly specified optimizing model such as the one worked out by Rezai, Foley, and Taylor (2012) is consistent with arguments in favor of sustainable consumption because it suggests that efforts at mitigation should take place early so that only ongoing emissions need to be mitigated in later periods. Such a policy decision could be built into simulations, or else $m$ might be treated as an increasing function of $\hat{\gamma}$ so that any acceleration in GHG accumulation would be promptly mitigated, perhaps forestalling a climate catastrophe of the sort discussed above.

\section{Conclusion}

We develop a demand-driven model to study the interactions between greenhouse gas (GHG) accumulation, global warming, and economic growth in a Post-Keynesian framework in order to avoid weaknesses of models usually deployed to address these issues. Our model captures the following elements: in the short run output and economic activity are determined by aggregate demand. Demand itself is essentially determined by the distribution of income between profits and wages. Over time the economy grows and its capital stock and productive capacity increase. Higher levels of income, however, require more energy use which, in the absence of climate policy, leads to higher GHG emissions. The model is used to study the behavior of the macroeconomy and the environment over time using the fundamental dynamics of the capital/population ratio and the GHG/capital ratio. Our analysis demonstrates that the interaction of greenhouse gas accumulation and economic growth is likely to involve cyclical boom-bust periods in output and a stabilization of atmospheric GHG at high levels to keep capital accumulation in check. The details of these aggregate dynamics, however, hinge on the 
dynamics of all the individual elements described above and would have to be studied in numerical calibration and simulation due to the model's complexity.

\section{References}

Goodwin, Richard M. (1967) “A Growth Cycle,” in C. H. Feinstein (ed.) Socialism, Capitalism, and Growth: Cambridge UK: Cambridge University Press.

Hirsch, Morris W, Stephen Smale, and Robert L. Devaney (2012) Differential Equations, Dynamical Systems, and Introduction to Chaos, New York: Academic Press.

Jackson, Tim (2009) Prosperity without Growth? The Transition to a Stable Economy, London: Sustainable Development Commission.

Kalecki, Michal (1971) Selected Essays on the Dynamics of the Capitalist Economy, 1933-1940, Cambridge UK: Cambridge University Press.

Kaldor, Nicholas (1957) “A Model of Economic Growth, Economic Journal, 67: 594-621.

Kaldor, Ncholas (1978) "Causes of the Slow Rate of Growth of the United Kingdom” in Further Essays on Economic Theory, London: Duckworth.

Keynes, John Maynard (1936) The General Theory of Employment, Interest, and Money, London: Macmillan.

Nordhaus, William D. (2010) A Question of Balance: Weighing the Options on Global Warming Policy, New Haven CT: Yale University Press.

Rezai, Armon, Duncan K. Foley, and Lance Taylor (2012) "Global Warming and Economic Externalities," Economic Theory, 49: 329-351.

Rezai, Armon, Lance Taylor, and Reinhard Mechler (2013) "Ecological Macroeconomics: An application to climate change," Ecological Economics, 85: 69-76.

Robinson, Joan (1974) History vs. Equilibrium, London: Thames Papers in Economics, Thames Polytechnic.

Samuelson, Paul A. (1965) "A Catenary Turnpike Theorem Involving Consumption and the Golden Rule, American Economic Review, 55: 486-496.

Schor, Juliet B. (2010) Plenitude: The New Economics of True Wealth, New York: Penguin.

Sen, Amartya K. (1966) "Peasants and Dualism with or without Surplus Labor, Journal of Political Economy, 74: 425-450.

Smil, Vaclav (2005) Energy at the Crossroads: Global Perspectives and Uncertainties, Cambridge MA: MIT Press. 
Taylor, Lance (2009) “Energy Productivity, Labor Productivity, and Global Warming," in Jonathan M. Harris and Neva R. Goodwin (eds.) Twenty-First Century Macroeconomics: Responding to the Climate Challenge, Northhampton MA: Edward Elgar.

Taylor, Lance (2010) Maynard's Revenge: The Collapse of Free Market Macroeconomics, Cambridge MA: Harvard University Press.

Victor, Peter A. (2008) Managing Without Growth: Slower by Design, Not Disaster, Cheltenham UK: Edward Elgar.

Waggoner, Paul E. and Jesse H. Ausubel (2002) “A framework for sustainability science: A renovated IPAT identity," PNAS 99: 7860-7865. 


\section{Appendix I: Rich and Poor Countries}

Rapid current economic growth rates for well-performing developing countries suggest that they are driving up the worldwide level of GHG accumulation; the evidence is less clear for the industrialized world. This line of thought can be pursued one step further. Let $i=R, P$ be an index for rich and poor regions, and define $v_{i}$ as $v_{i}=\left(\chi_{i} / \varepsilon_{i}\right)-\psi_{i}\left(m_{i}\right) m_{i}$. Expanding upon (11) the overall change in GHG emission becomes

(A.1) $\dot{G}=\left(v_{R} x_{R}+v_{P} x_{P}\right) X-\omega G$

with $x_{i}=X_{i} / X$ where the $X_{i}$ are regional output levels.

A clear distributive conflict pivots around how to allocate the cost of mitigation between rich and poor countries. Equation (A.1) shows how to decompose worldwide GHG expansion into contributions from the regions. Figure 8 is an exaggerated hypothetical illustration about how the contributions might change as overall output increases. The solid lines represent "business as usual" (BAU). For "low" (or early $21^{\text {st }}$ century) levels of output most GHG emission comes from rich countries and the contribution of poor countries is small. For "high" (mid $21^{\text {st }}$ century?) outputs with BAU the situation changes, as poor countries contribute most of the growth of GHG.

\section{Figure A1}

The dashed lines show a mitigation scenario in which the poor country contribution drops off notably on the assumption that decreasing returns to mitigation are less onerous in economies which use relatively low levels of energy in production, often under conditions of low efficiency. Trade-offs about how and where mitigation should be pursued immediately arise. 


\section{Appendix II: Supply-driven Growth}

Most discussion by economists about global warming is framed in terms of supply-side economics. It makes sense to sketch how these models differ from the analysis herein.

In the short run, Say's Law is the fundamental mainstream assumption. Instead of being determined residually as the difference between output and productivity growth rates, the growth rate $n$ of employment (now set equal to population $N$ ) is specified exogenously. The usual response to this extra restriction (or $L=N$ ) is to drop an independent investment function such as the one used in this paper, $I=\left(g_{0}+\alpha \pi u\right) K$. Basically, investment is determined by available full-employment saving or the "forces of productivity and thrift."

Output per capita is $X / N=x=f(\kappa)$ with $f(\kappa)$ as an aggregate neoclassical production function with constant returns to scale. The relationships among employment, the profit share, and investment in the demand-driven model are replaced by an assumption that the profit rate $r$ is equal to the marginal product of capital, $r=f^{\prime}(\kappa)$. It is also assumed that $f^{\prime \prime}<0$ in recognition of "diminishing returns" to capital. Income distribution is determined by these behavioral relationships.

If $C=s X, c=C / N$, and we set $M=\mu K$ the standard neoclassical accumulation equation is

$$
\dot{\kappa}=x-c-(\mu+n+\delta+\hat{\xi}) \kappa=s f(\kappa)-(\mu+n+\delta+\hat{\xi}) \kappa
$$

so that the increase in the capital/labor ratio is equal to saving per capita less mitigation spending per capita $\mu \kappa$, a term in $n \kappa$ which represents extra output needed to offset population growth, and depreciation $\delta k$. Saving also has to compensate for implicit job loss $\hat{\xi} \kappa$ caused by productivity growth. Over time, however, higher productivity shifts the production function upward.

The condition for a steady state at $\dot{\kappa}=0$ is

(B.2) $s f(\kappa)=(\hat{\xi}+\mu+n+\delta) \kappa$

Because $s f(\kappa) / \kappa=s u$, this equation can be rewritten as

$$
s u=n+\delta+\widehat{\xi}+\mu \quad .
$$


Recalling from (9) that the steady state investment/capital ratio in the demand-driven model is $g=n+\delta$, the contrast between the two approaches becomes clear - in the long run labor productivity growth feeds into investment and output in the supply-side model and into falling employment in a demand-driven specification

There are two standard mainstream growth models. In the Solow-Swan variant the saving rate $s$ is assumed to be constant. In optimal growth models à la Nordhaus (2010) the rate is determined by dynamic optimization (more details below), and so is fixed to any point in time. Either way, $\dot{\kappa}$ in (B.1) adjusts to guarantee macro balance. Higher mitigation spending $m$ cuts into capital accumulation because $x$ and $u$ are fixed from the supply side. In the demand-driven model, on the other hand, more mitigation raises the output level and stimulates growth.

In the short run shown in Figure 9, the macro balance schedule $u(\pi)$ is a vertical line because Say's Law fixes output independent of $\pi$. The level of $\pi$ in turn is determined by the marginal productivity condition $r=f^{\prime}(\kappa)$ and the accounting identity $r=\pi u$. An important mainstream parameter is the "elasticity of substitution" $\sigma$. If $\sigma<1$ (the typical assumption), the distribution schedule $\pi(u)$ has a positive slope - higher capacity utilization caused by higher employment raises the profit share. The widely used "Cobb-Douglas" production function sets $\sigma=1$ and holds $\pi$ constant so $\pi(u)$ becomes a horizontal line.

\section{Figure 9}

It is interesting to compare how demand- and supply-driven models respond to exogenous changes in key variables. A neoclassical damage function is based on the assumption that higher GHG concentration cuts directly into production, shifting the $u(\pi)$ schedule to the left, reducing $u$ and (if the production function is not Cobb-Douglas) $\pi$. A lower level of labor productivity would have the same effects. The directions of movement in $u$ and $\pi$ are the same as those in the demand-driven model in Figure 1 but the mechanisms differ. The demand side narrative focuses on shifts in the distributive $\pi(u)$ schedule while mainstream analysis is based on movements in the (vertical) supply curve $u(\pi)$. 
Finally, capital may be destroyed by higher GHG concentration. With a neoclassical production function featuring decreasing returns $X$ will fall less than in proportion to $K$ so that $u$ will increase. A rightward shift of the $u(\pi)$ schedule in Figure 9 would lead to an increase in the profit share although both output and employment would go down. The signs of changes are the same as in the demand-driven model but in Figure 1 they would result from an upward shift in the $\pi(u)$ curve instead of the change in $u(\pi)$ in Figure 9.

Optimizing neoclassical climate change models basically use the production theory just stated and energy/GHG accounting like that in the text. They further assume that a representative agent with a very long time horizon chooses "control variables" $s$ and $m$ to maximize an integral of discounted utility from consumption over time. The full specification generates saddlepoint dynamics as in Figure 6 for "state variables" such as $\kappa$ and $\gamma$, except that somewhat miraculously the system moves toward the saddlepath SS and stays close to the steady state at Z. In the literature this characteristic is known as the "turnpike" property (Samuelson, 1965) which assures that trajectories of state variables in finite horizon optimal programs mimic their infinite horizon analogs for long periods of time.

Smooth evolution of state variables does not, however, guarantee small variations for controls. In the fully optimal solutions described by Rezai, Foley, and Taylor (2012), for example, $s$ drops from around 0.3 to 0.1 over the planning horizon, while mitigation spending as a fraction of output declines from around 0.02 to 0.01 . Such behavior is characteristic of many dynamic optimization exercises in which capacity-building activity such as capital formation and mitigation is "frontloaded" in solutions because it generates benefits over the model's full time horizon. Because of quirks in its specification Nordhaus's (2010) model does not demonstrate this sort of behavior.

A final note is that an optimization exercise also typically irons away the potentially unstable and cyclical dynamics illustrated in Figures 5-7, for better understanding or for worse. Whether these aspects of the mainstream narrative make practical sense is best left for the reader to ponder. 
Figures

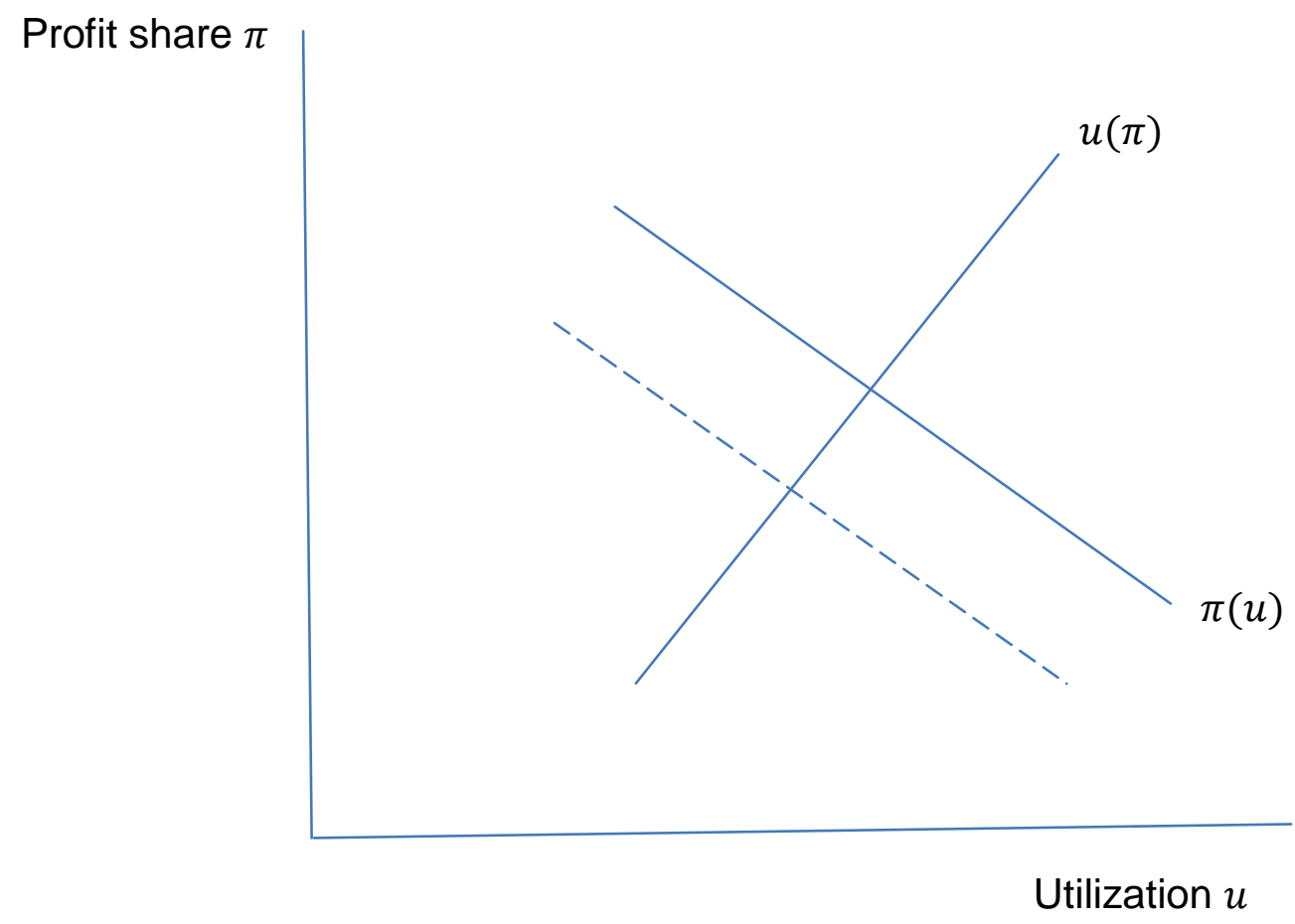

Figure 1: Relationships between capacity utilization and the profit share. The shift in the $\pi(u)$ schedule could be due to higher GHG concentration or lower labor productivity. 


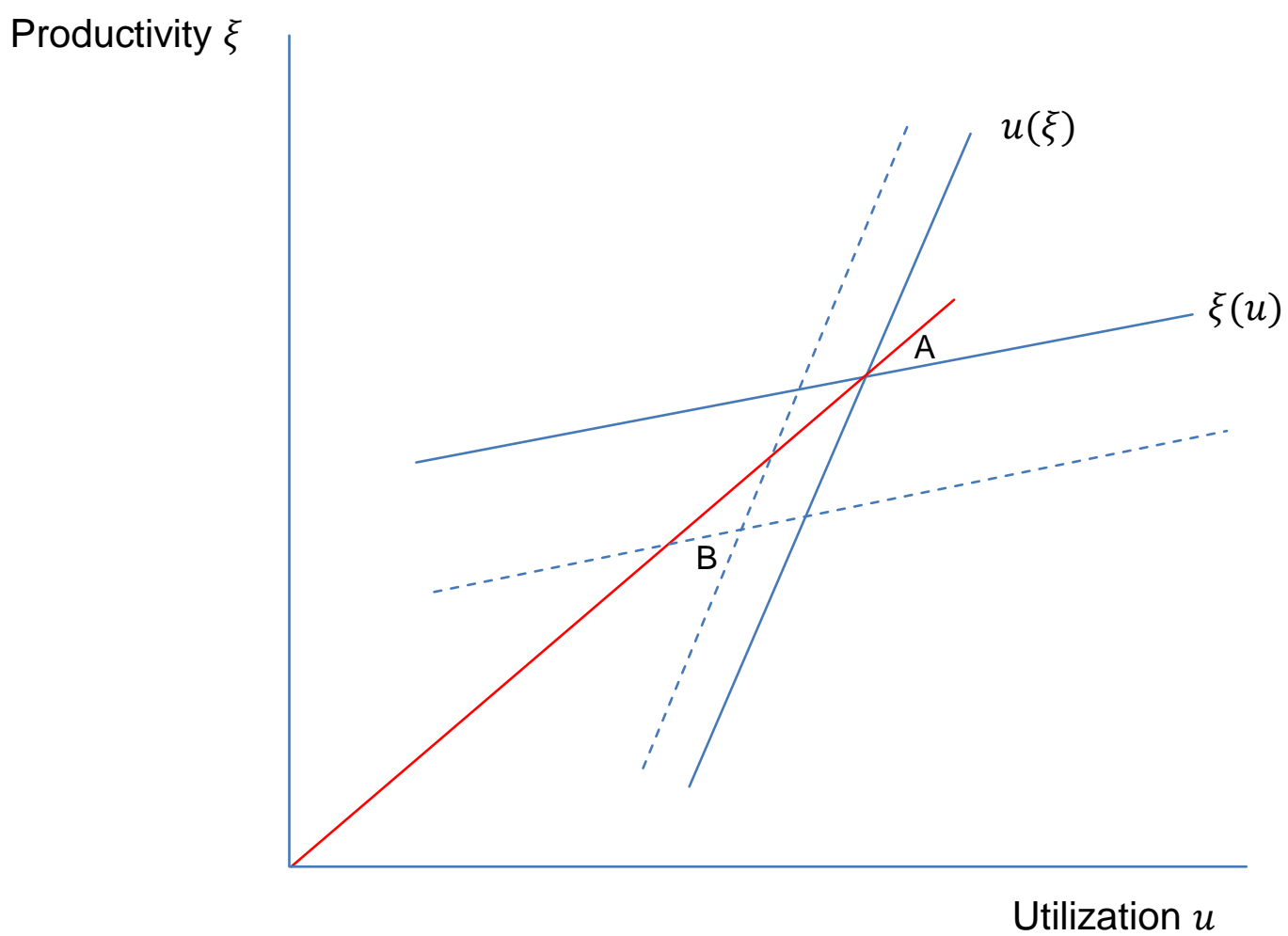

Figure 2: Effects of higher GHG concentration on capacity utilization and productivity when there is a dominant Kaldor effect of $u$ on $\xi$. The diagram shows a case in which employment increases. 


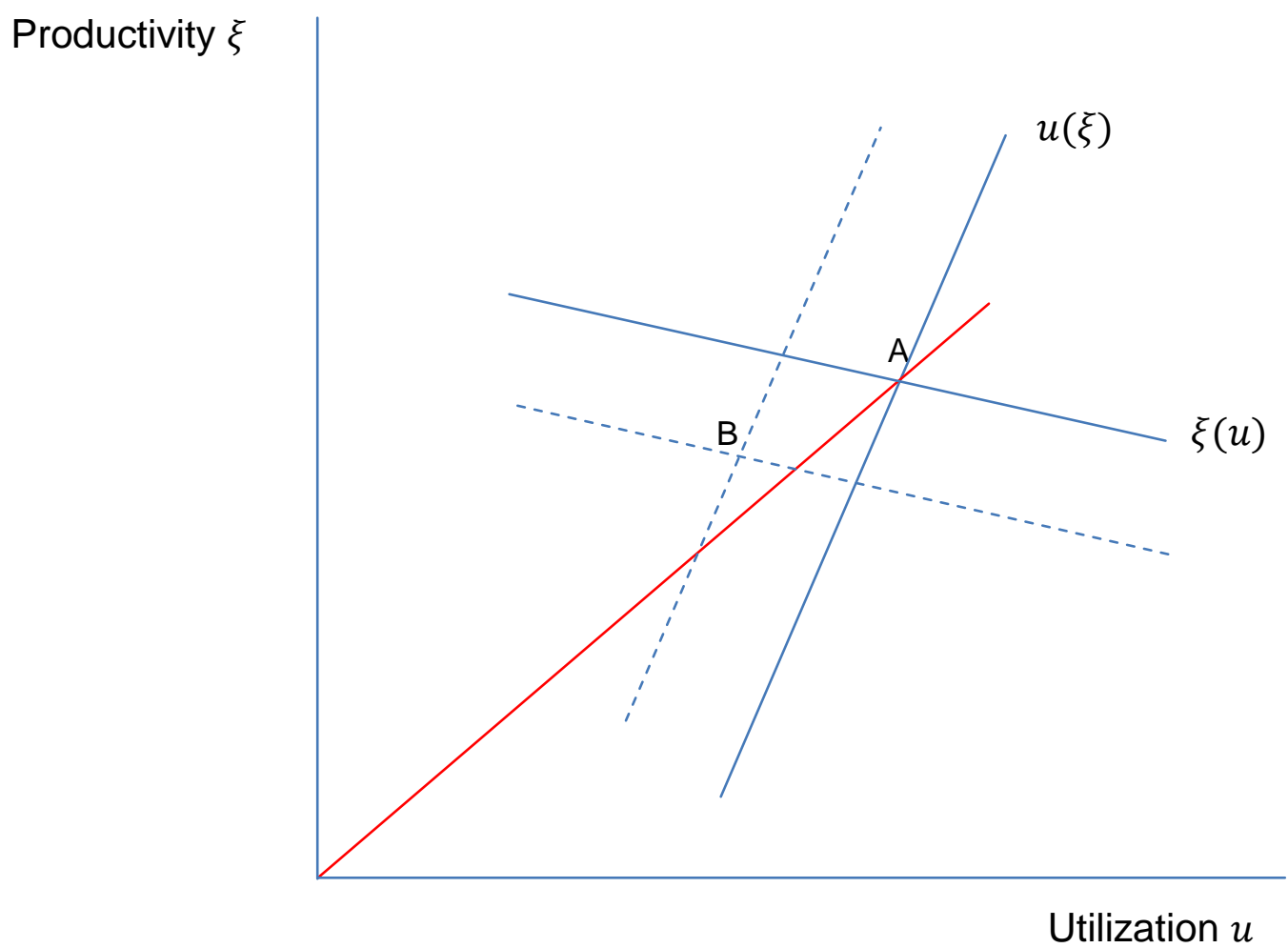

Figure 3: Effects of higher GHG concentration on capacity utilization and productivity when there is a dominant SenSchor effect of $u$ on $\xi$. The diagram shows a case in which employment decreases. 


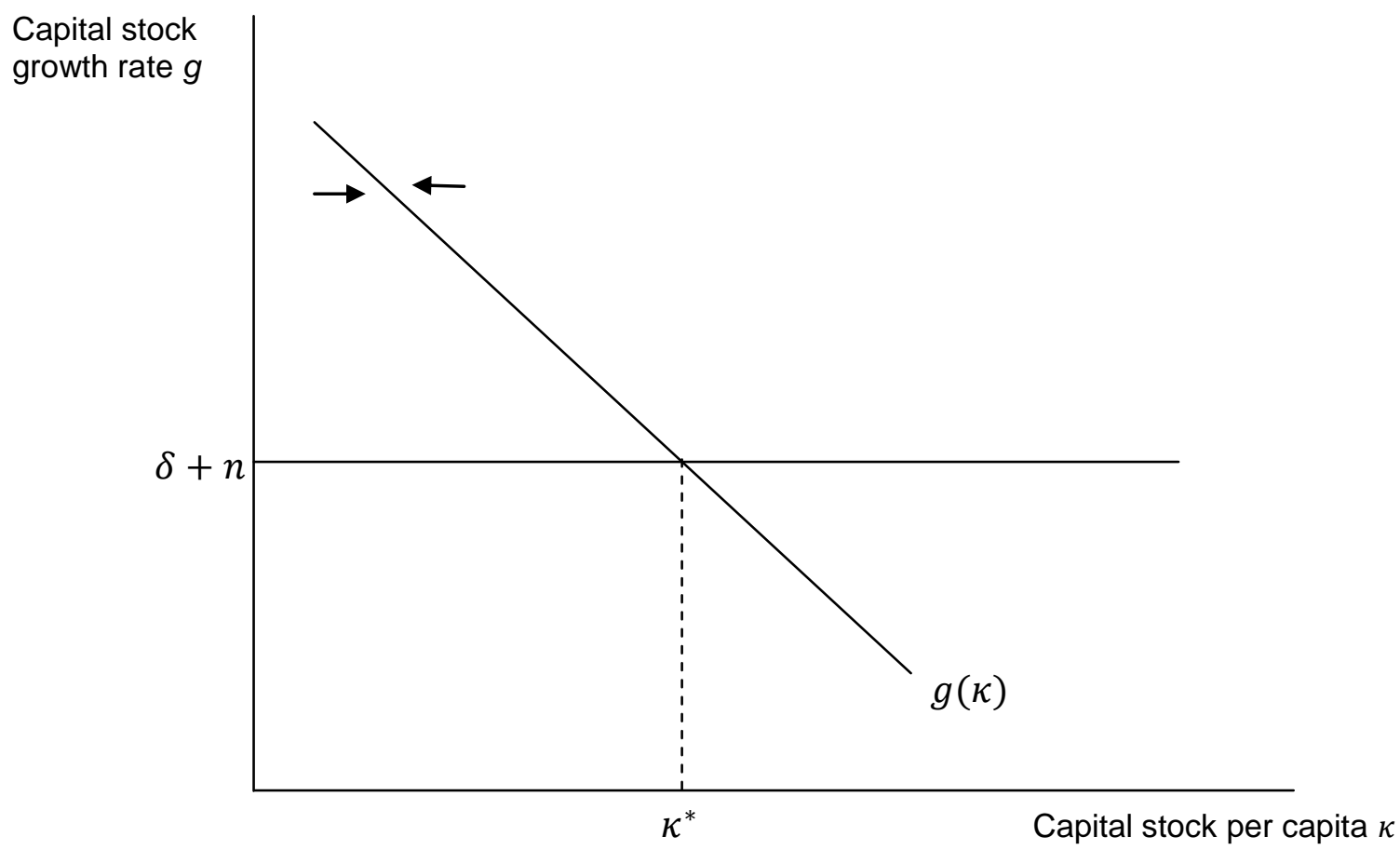

Figure 4: Dynamics of growth of the capital/population ratio $\kappa$ 


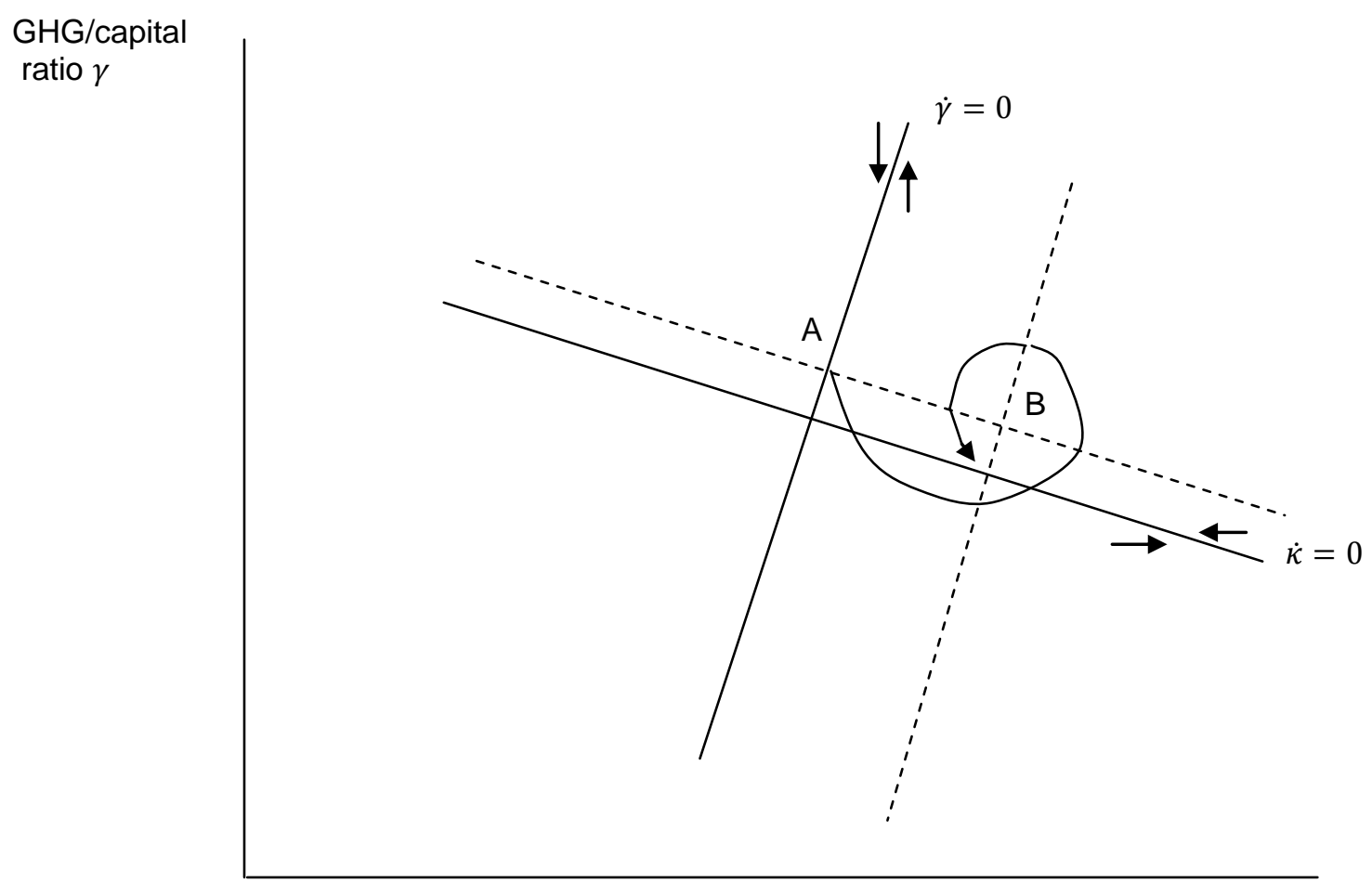

Capital stock per capita $\kappa$

Figure 5: Cyclical dynamics of growth of the capital/population ratio $\kappa$ and the GHG/capital ratio $\gamma$ 


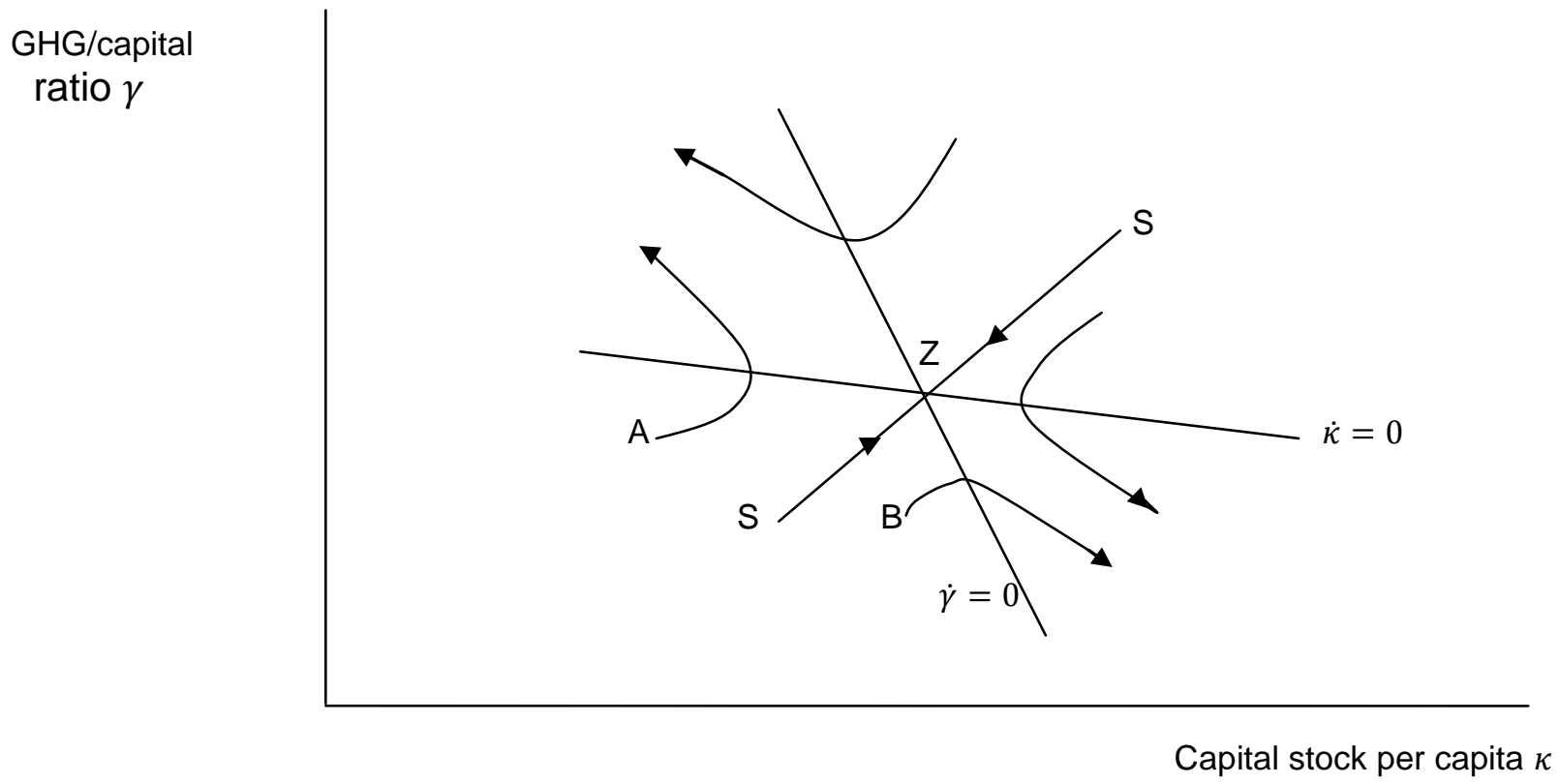

Figure 6: Non-converging saddlepoint dynamics of growth of the capital/population ratio $\kappa$ and and GHG/capital ratio $\gamma$ 


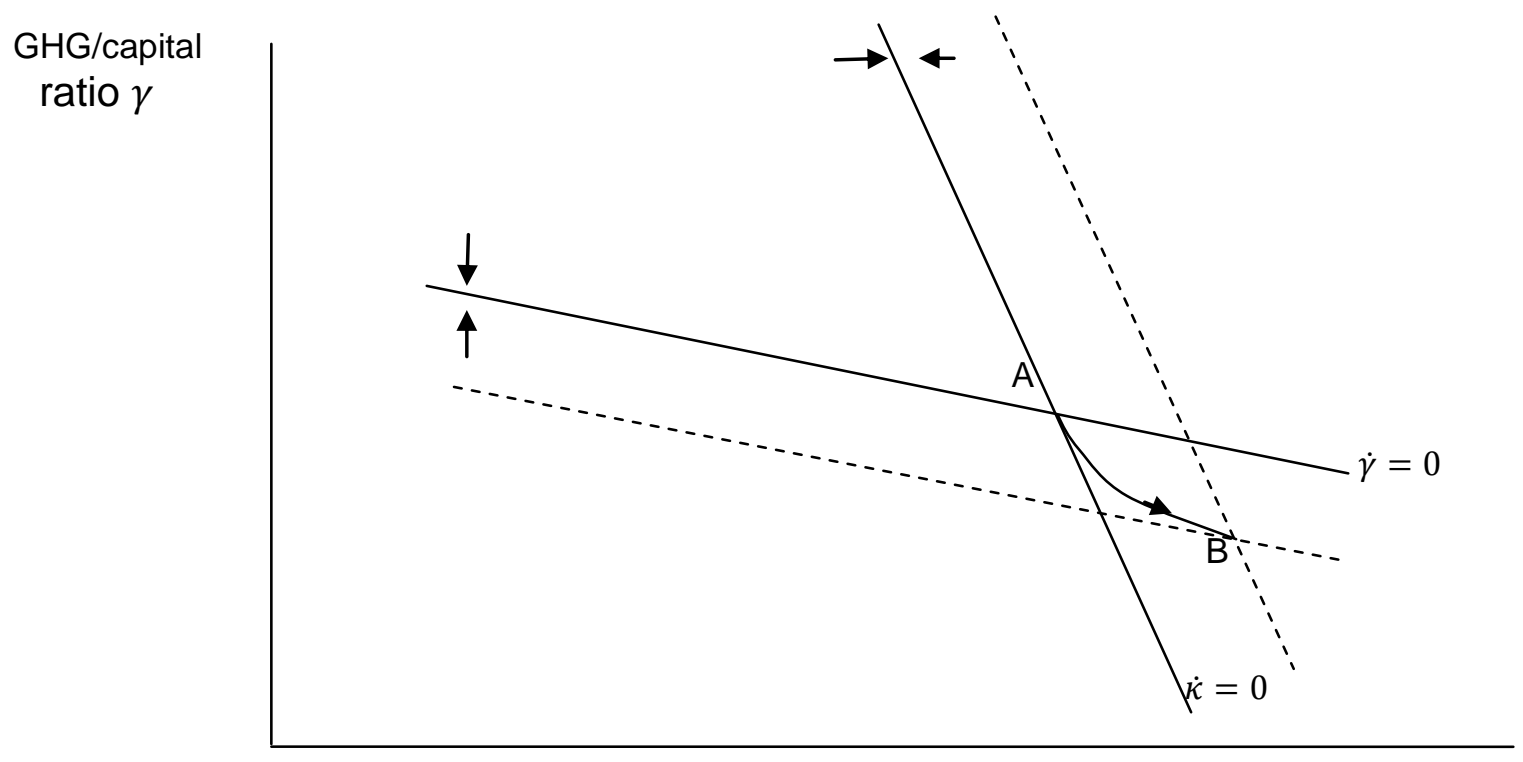

Capital stock per capita $\kappa$

Figure 7: Stable non-cyclical dynamics of growth of the capital/population ratio $\kappa$ and and GHG/capital ratio $\gamma$ 


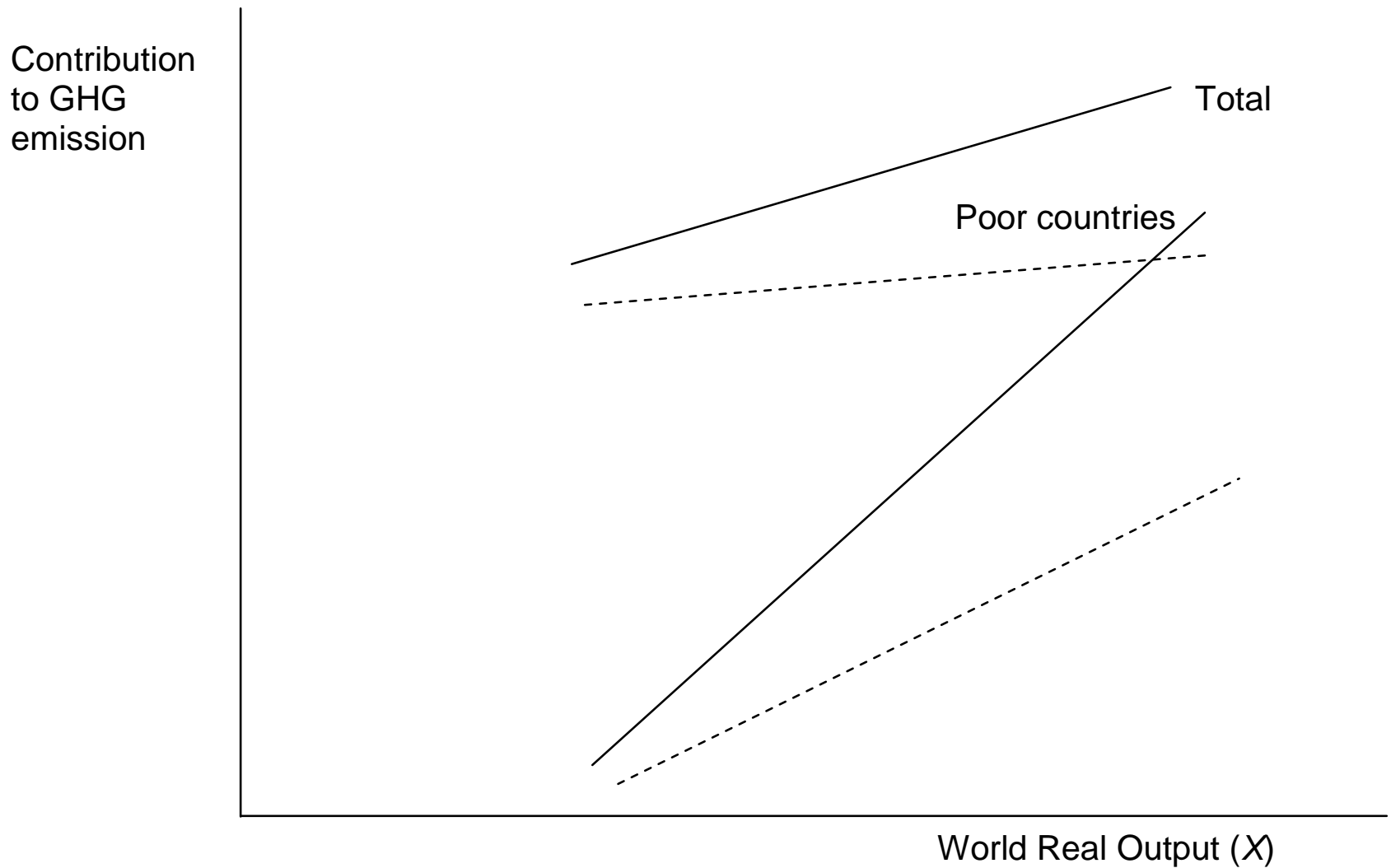

Figure A1: Hypothetical contributions to GHG emission 


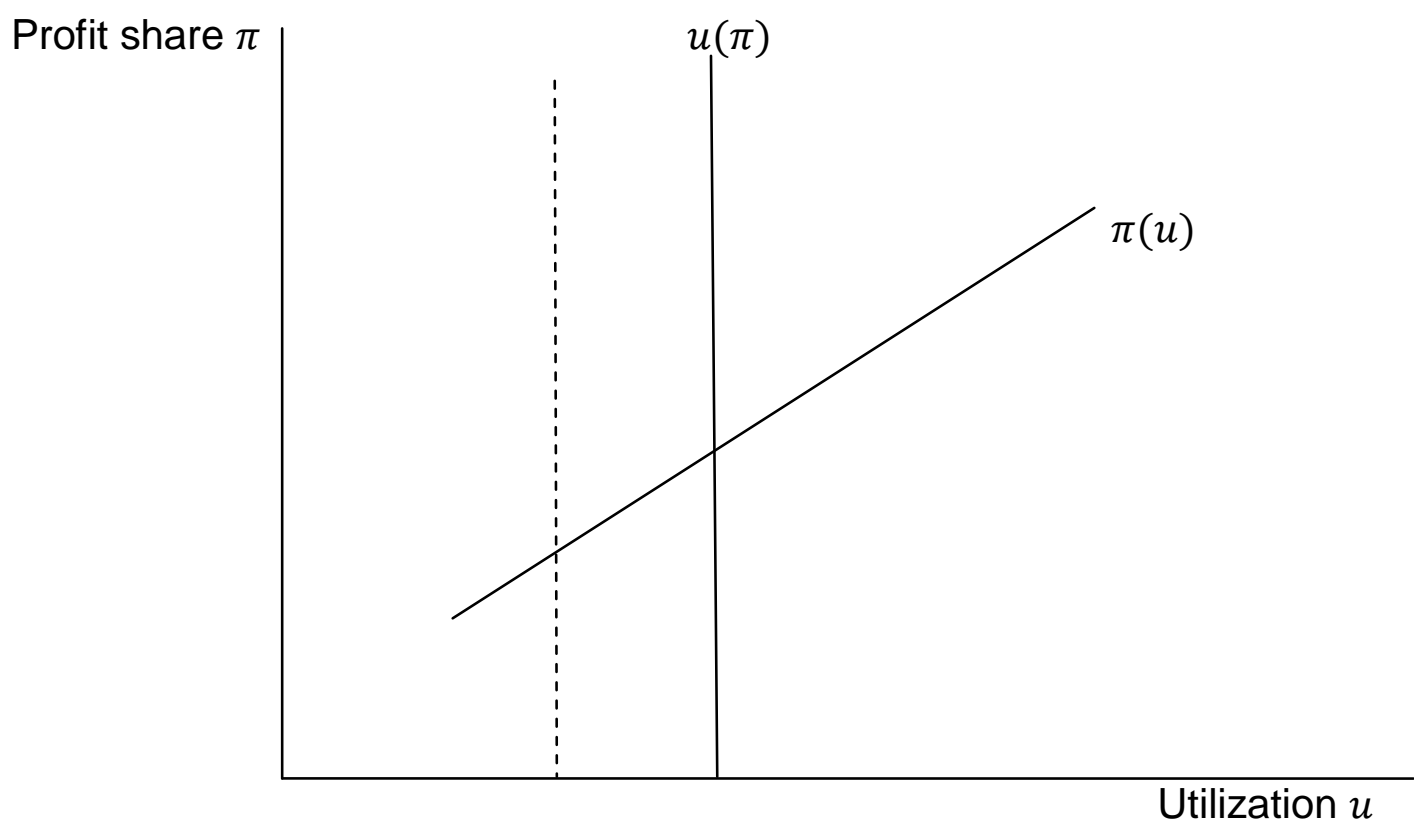

Figure B1: Relationships between capacity utilization and the profit share in a mainstream macro model. The shift in the $u(\pi)$ schedule 